TO BE PRESENTED AT THE FOURTEENTH INTERNATIONAL CONFERENCE ON MAGNET TECHNOLOGY

TAMPERE, FINLAND JUNE I1-16, 1995

\title{
The Magnet System of the Relativistic Heavy Ion Collider (RHIC)
}

\author{
A. Greene, M. Anerella, J. Cozzolino, J. Escallier, D. Fisher, G. Ganetis, A. Ghosh, R. Gupta, A. Jain, S. Kahn, E. \\ Kelly, R. Lebel, G. Morgan, A. Morgillo, S. Mulhail, J. Muratore, S. Plate, A. Prodell, M. Rehak, W. Sampson, R. \\ Thomas, P. Thompson, P. Wanderer, E. Willen \\ Brookhaven National Laboratory, Upton, New York 11973-5000 USA
}

\begin{abstract}
The Relativistic Heavy Ion Collider now under construction at Brookhaven National Laboratory (BNL) is a colliding ring accelerator to be completed in 1999. Through collisions of heavy ions it is hoped to observe the creation of matter at extremely high temperatures and densities, similar to what may have occurred in the original "Big Bang". The collider rings will consist of 1740 superconducting magnet elements. Some of these elements are being manufactured by industrial partners (Northrop Grumman and Everson Electric). Others are being constructed or assembled at BNL. A description is given of the magnet designs, the plan for manufacturing and test results. In the manufacturing of the magnets, emphasis has been placed on uniformity of their performance and on quality. Results so far indicate that this emphasis has been very successful.
\end{abstract}

\section{INTRODUCTION}

The Relativistic Heavy Ion Collider (RHIC) will be used to study the collisions of heavy ions at energies that range up to $100 \mathrm{GeV} / \mathrm{u}$ per beam. The center-of-mass energies of these collisions will exceed those of any other existing accelerator of heavy ion beams by more than a factor of ten. Physics studies will observe conditions of temperature and matter density believed to have existed during the formation of the early universe. Under such conditions nuclear matter is predicted to undergo a transition from a system of neutrons and protons to a plasma of quarks and gluons.

The RHIC Collider is being constructed on the site of Brookhaven National Laboratory (BNL) on Long Island, New York. It will utilize numerous existing facilities that are already used to study heavy ion collisions with fixed targets. These include a Tandern Van de Graaff accelerator, a heavy ion transfer line to a booster accelerator and the Alternating Gradient Synchrotron (AGS). Construction of RHIC began in 1991 and is expected to be completed in 1999 . Total construction cost to complete the RHIIC accelerator complex, including construction of two major experiments, is $\$ 500 \mathrm{M}$; the magnet system cost will be $\$ 150 \mathrm{M}$. The range of ion species to be accelerated and collided is protons up to ${ }^{197} \mathrm{Au}$.

The RHIC collider will consist of two concentric, side-byside rings of superconducting magnets in an existing tunnel with a circumference of $3.8 \mathrm{~km}$. The tunnel and lattice provide intersections at six locations around the circumference where experiments can be located. In the two rings there are 396 dipoles, 492 quadrupoles, 72 trim quadrupoles, 288 sextupoles,

Manuseript received June 12, 1995.

This work supported in part by the U.S. Department of Energy under Contract No. DE-AC02-76CH00016. and 492 magnets to correct field perturbations. The goal for the magnet building effort is to construct, utilizing industrial capability and BNL expertise, the total of 1740 magnet elements of the quality and uniformity to create an excellent accelerator facility. Spare magnets are produced in addition to these. A single $24.8 \mathrm{~kW}$ refrigerator (existing) and cryogenic system are designed to maintain magnet temperatures below $4.6 \mathrm{~K}$.

\section{SUMMARY OF THE MAGNET DESIGNS}

\section{A. Standard Aperture Dipoles - 360 total}

These magnets have a coil aperture of $8 \mathrm{~cm}$. [1,2]. They consist of 264 arc dipoles that are $9.7 \mathrm{~m}$ long, 24 insertion dipoles that are identical to the are dipoles, and 72 other insertion dipoles that are identical in cross section but of three shorter lengths: $2.95,6.92$ and $8.71 \mathrm{~m}$. These dipoles were designed by BNL and are being constructed by an industrial partner, Northrop Grumman Corporation, also located on Long Island. The details of this very successful industrial production are given in more detail in another paper at this conference [3]. The standard aperture dipole cold mass is shown in Fig. 1. It has a measured central field of $3.40 \mathrm{~T}$ at an operating current of $5.0 \mathrm{kA}$. [Injection field is $0.40 \mathrm{~T}$ at $0.57 \mathrm{kA}$.]

The single-layer coil of the magnets consists of 32 turns with three copper wedges. The 30-strand cable was purchased by BNL from Oxford Superconducting Technology of Carteret, NJ and provided to Northrop Grumman; their cabling subcontractor was New England Electric Wire Corp. of Lisbon, NH [4]. The cable insulation is a double-wrap of Kapton CI polyimide with polyimide adhesive [5]. Surrounding the coils are Rogers Corp. RX630 glass-filled phenolic insulators that provide the pole angle, insulation to ground and separation of the coils from the iron to reduce saturation effects. The iron yoke also serves as a collar for the coil at assembly; the laminations are $6.35 \mathrm{~mm}$ thick. Yoke containment is partially provided by stainless steel shell halves welded to provide a $48.5 \mathrm{~mm}$ sagitta and to assure mechanical integrity of the cold mass at cryogenic temperatures. End plates $31.8 \mathrm{~mm}$ thick are welded to the shells and provide axial force on the coils.

The dipole cold mass is contained vertically off-centered by $90 \mathrm{~mm}$ inside a steel vacuum vessel of $610 \mathrm{~mm}$ outer diameter. The off-centered cold mass can create a skew quadrupole harmonic at high field. This has been reduced as discussed in more detail elsewhere at this conference [6]. Also included in the vacuum vessel are a single $55 \mathrm{~K}$ heat shield, MLI blankets, 


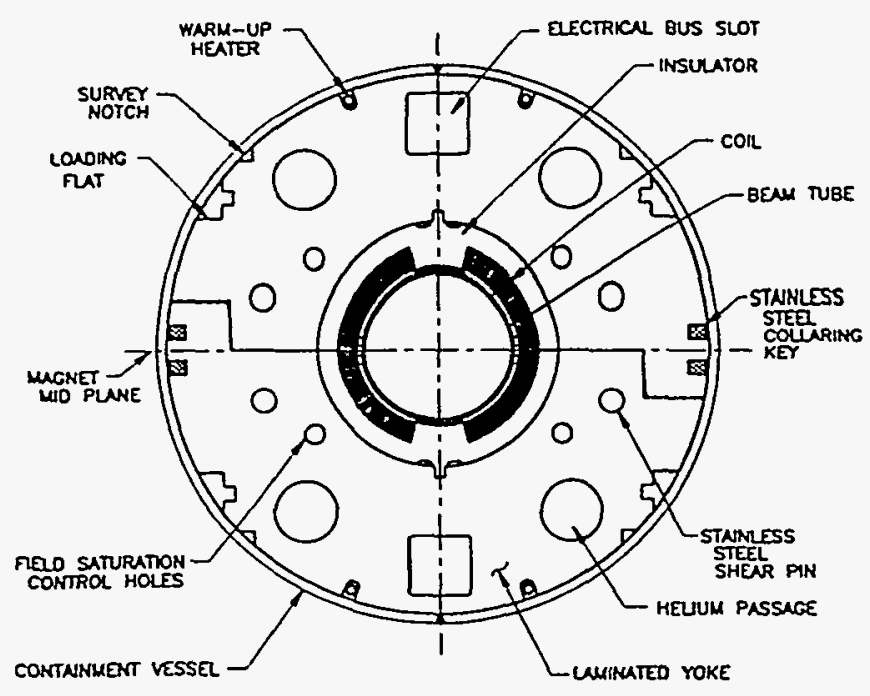

Fig. 1. RHIC standard aperture $(8 \mathrm{~cm})$ dipole cold mass.

and helium supply, return and utility pipes. The dipole cold mass is supported at three locations on posts molded from General Electric Co. Ultem 2100.

\section{B. Standard Aperture Corrector-Quadrupole-Sextupole (CQS) Assemblies - 420 total}

The CQS magnet assemblies alternate with the standard aperture dipoles to form the arc regions of the accelerator. The CQS assembly consists of a separate cold mass unit supported inside a cryostat vacuum vessel very similar to that for the dipole, but with two support posts [7]. There are 80 different styles of CQS assemblies, each customized for its location in the accelerator lattice. The more common styles consist of a four-multipole concentric corrector used for field corrections, a quadrupole for horizontal or vertical focusing, and a sextupole for chromaticity correction. For some CQS assemblies in the insertion regions, sextupoles are replaced by 72 individually powered trim quadrupoles that are used to vary the machine tune in those regions.

Also included in each CQS assembly is a BNL-fabricated beam position monitor. For 60 of the CQS assemblies a recooler is located within the $55 \mathrm{~K}$ heat shield of the cryostat. Heat is removed from the circulating helium stream by heat exchange with a boiling liquid helium bath in the recoolers. The CQS assemblies are manufactured at BNL from components described below. .

1) Standard Aperture Corrector Magnets - 420 total: The magnets [8] are made at BNL of coils wound by a computercontrolled winding machine that relies on ultrasonic energy to ${ }^{\circ}$ attach the adhesive-coated wire to a flat Kapton/b-stage epoxy substrate (Fig. 2). The coils then precisely envelop a stainless steel support tube and are wrapped with glass tape and Kevlar yarn at 12.6 turns $/ \mathrm{cm}$ and $98 \mathrm{~N}$ tension to provide prestress. The support tubes are concentrically assembled inside iron

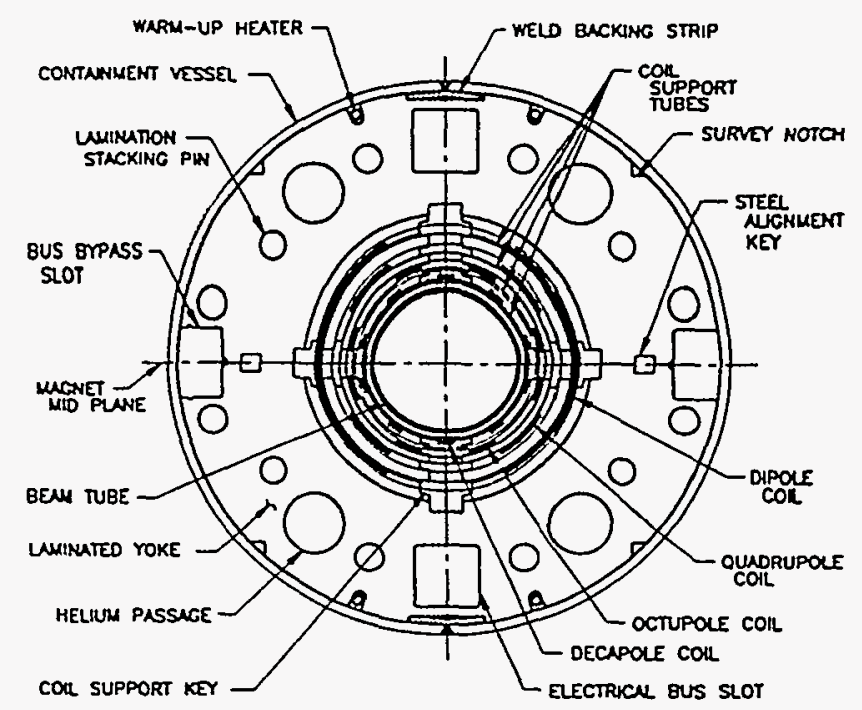

Fig. 2. RHIC standard aperture $(8 \mathrm{~cm})$ corrector cold mass.

laminations welded together from half-yokes with carefully controlled weights.

The superconductor wire is $0.33 \mathrm{~mm}$ diameter with copperto-superconductor ratio of $2.5: 1$ and with $10 \mu \mathrm{m}$ filaments. It is wrapped with $50 \%$ overlap $25 \mu \mathrm{m}$ thick Kapton and is coated on the outside with $12 \mu \mathrm{m}$ Bondall adhesive. The wire is wound onto a flat epoxy-coated substrate surface consisting of $0.076 \mathrm{~mm}$ thick Kapton and $0.20 \mathrm{~mm}$ thick b-stage epoxy filled with glass fibers; spacing between wires is $0.15 \mathrm{~mm}$. A second layer of wire is wound on top of and nested between the first layer turns. Although some corrector magnets consist of only a horizontal or a vertical deflecting dipole assembly, others consist of four keyed concentric tubes.

2) Standard Aperture Quadrupole Magnets - 420 total: Quadrupoles in the arcs of the accelerator have magnetic length of $1.11 \mathrm{~m}$, while others in the insertion regions also include lengths of 0.93 and $1.81 \mathrm{~m}$ [1]. The gradient at top energy operation is $71 \mathrm{~T} / \mathrm{m}$. A cross section of the cold mass is given in Fig. 3; the coils consist of 16 turns and one copper wedge. The quadrupoles use most features of the dipole design - the same superconductor cable and Kapton insulation, phenolicglass spacers between coils and iron, and an iron yoke used as a collar for assembly. Another paper at this conference describes the detailed features of these magnets that are being produced by Northrop Grumman Corporation [3].

\section{3) Standard Aperture Sextupole and Trim Quadrupole} Magnets - 288 and 72 total, respectively: These magnets (Fig. 4) are of similar design with iron pole tips [9]. They are manufactured by Everson Electric Co. of Bethlehem, PA. The coils consist of 200 turns of superconductor wire racetrack wound onto a bobbin machined from G-10 CR. Between 
,

DISCLAIMER

This report was prepared as an account of work sponsored by an agency of the United States Government. Neither the United States Government nor any agency thereof, nor any of their employees, makes any warranty, express or implied, or assumes any legal liability or responsibility for the accuracy, completeness, or usefulness of any information, apparatus, product, or process disclosed, or represents that its use would not infringe privately owned rights. Reference herein to any specific commercial product, process, or service by trade name, trademark, manufacturer, or otherwise does not necessarily constitute or imply its endorsement, recommendation, or favoring by the United States Government or any agency thereof. The views and opinions of authors expressed herein do not necessarily state or reflect those of the United States Government or any agency thereof. 


\section{DISCLAIMER}

Portions of this document may be illegible in electronic image products. Images are produced from the best available original document. 


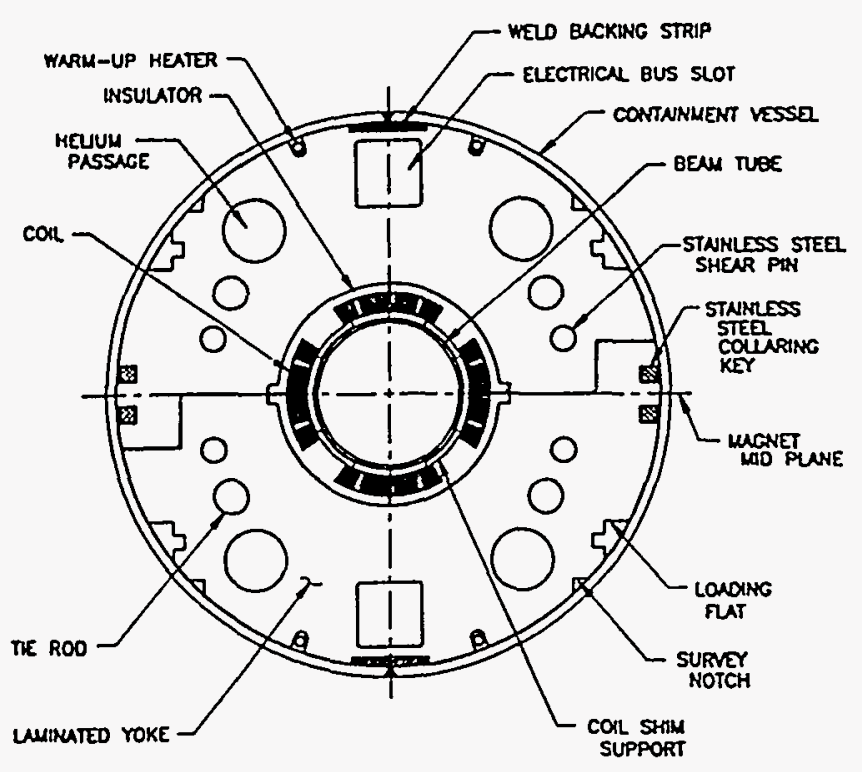

Fig. 3. RHIC standard aperture $(8 \mathrm{~cm})$ quadrupole cold mass.

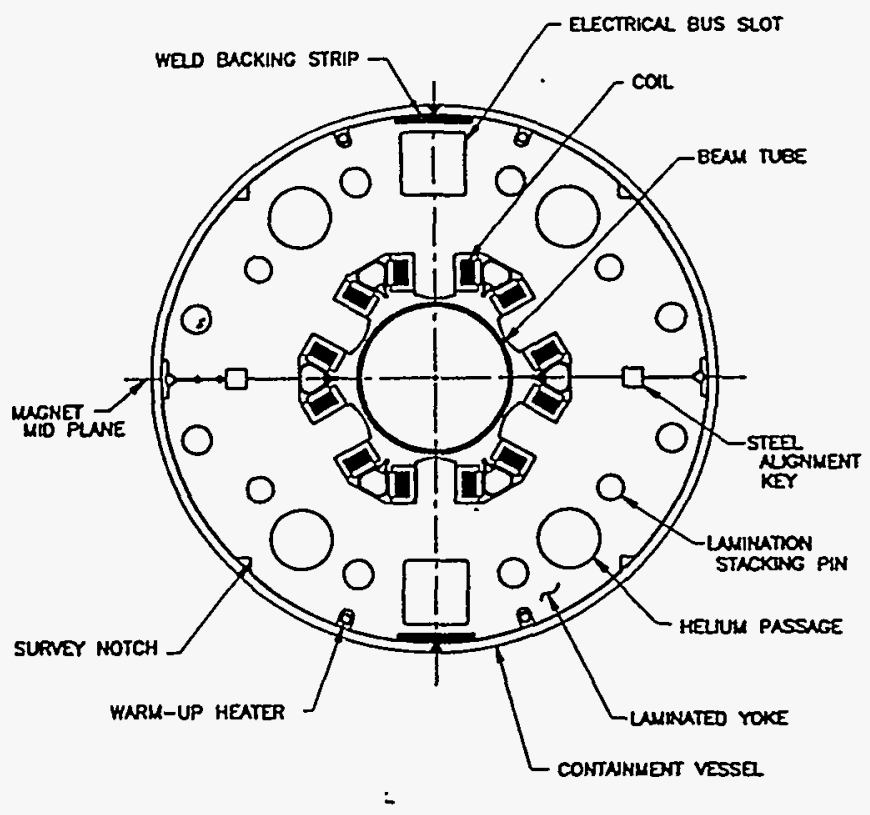

Fig. 4. RHIC standard aperture $(8 \mathrm{~cm})$ sextupole cold mass.

winding layers, epoxy and glass tape are applied; coils are then cured under pressure when winding is complete. The requisite six or four coils are secured inside iron yoke-halves which are then welded together. Superconductor wire is $0.51 \mathrm{~mm}$ diameter with copper-to-superconductor ratio of 3.0:1 and with $10 \mu \mathrm{m}$ filaments. Insulation is $25 \mu \mathrm{m}$ thick Kapton with $50 \%$ overlap.

\section{Large Aperture Quadrupole-Corrector Assemblies - 72 total}

Three $13 \mathrm{~cm}$ aperture quadrupole-corrector assemblies are located on either side of all six of the interaction regions. The quadrupoles form a "triplet" and perform the final strong focusing for the experiments. Attached to two of the quadrupoles are $13 \mathrm{~cm}$ corrector magnets. The quadrupolecorrector units will be produced as completed cold mass assemblies with helium containment shells and end volumes. Assembly will be completed in the RHIC accelerator tunnel when six units are placed into a large, split cryostat. These magnet assemblies are being constructed at BNL.

1) Large Aperture Quadrupole Assemblies - 72 total: For these $13 \mathrm{~cm}$ aperture quadrupoles, the required maximum operating gradient is $48 \mathrm{~T} / \mathrm{m}$ and the magnetic lengths are 1.44 , 2.10 and 3.40 meters. See Fig. 5 for a cross section of the cold mass [10]. Each coil consists of 27 turns of superconductor cable wrapped with the same insulation as that for the standard aperture cable magnets; there are two copper wedges. The cable has 36-strands of $0.648 \mathrm{~mm}$ diameter wires with copperto-superconductor ratio of $1.8: 1$ and $6 \mu \mathrm{m}$ filaments. The mechanical configuration is similar to that of standard aperture cable magnets. At eight locations between the phenolic-glass and iron are spaces where magnetic "tuning shims" will be located. These shims, consisting of iron and brass laminations, will be used to make critical field quality corrections after the magnets are assembled and magnetically measured (warm). A paper at this conference gives a description of these magnets and the innovative methods for fine adjustment of magnetic field harmonics [11].

2) Large Aperture Corrector Assemblies - 72 total: These magnets are to be constructed using methods very similar to those used for the standard aperture correctors. They also consist of four concentric support tube assemblies with dipole,

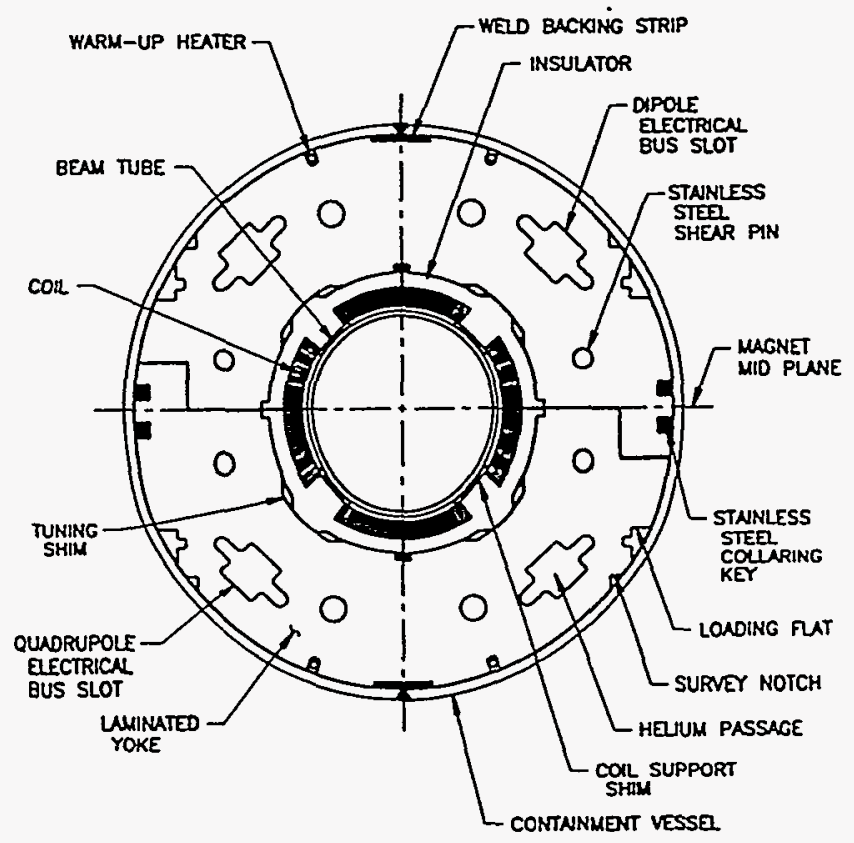

Fig. 5. RHIC large aperture $(13 \mathrm{~cm})$ quadrupole cold mass. 
quadrupole, sextupole, octupole, decapole and do-decapole windings.

\section{Large Aperture Dipole Assemblies - 36 total with two different apertures}

The DO dipole assemblies have a coil aperture of $10 \mathrm{~cm}$ and are $3.6 \mathrm{~m}$ long; their operating field is $3.52 \mathrm{~T}$. They are located in each ring on each side of the six interaction regions (24 total) and initiate the beam crossing for the experiments. The magnets have single layer coils and a sagitta of $7.6 \mathrm{~mm}$. Pairs of cold masses with apposite sagitta will be assembled in the accelerator tunnel in split-type cryostatl.

DX dipoles have an $18 \mathrm{~cm}$ aperture and $3.7 \mathrm{~m}$ length. There are twelve of these since both beams pass through them close to the interaction regions. They are assembled from single layer coils; design operating field is $4.28 \mathrm{~T}$. It is planned to provide coil prestress with self-supporting high-strength stainless steel collars. These will be surrounded by a horizontally-split iron yoke and a stainless steel shell with no sagitta. Again, cryostats will be assembled in the accelerator tunnel.

\section{PLAN FOR MAGNET MANUFACTURING}

The design of the magnets for RHIC is a culmination of ongoing magnet $R \& D$ at $B N L$ incorporating also ideas from other magnet programs, in particular HERA and the SSC. The main goal has been to provide high quality, cost-effective designs. All RHIC magnet R\&D was done at BNL and industrial confracts are built-to-print with BNL responsible for the design.

During the selection process of outside magnet manufacturers, quality and manufacturing capability were stressed. A review of controls was done to ensure the BNL's design and specifications, as well as the control of purchased material and manufacturing procedures set in place to provide for continuity of performance results. Regular quality audits and liaison with these suppliers provide confidence that these controls are working.

The BNL manufacturing was a major transition going from R\&D to production. During this period BNL looked at modern industry today and incorporated some of the best streamlined methods used: MRPII, Total Quality Management (TQM), Internal/External Customers, as well as employing a technique that reduces inspection (build it check it). During this period, in-house training was conducted for our management, engineers and technicians, in quality and manufacturing concepts and in controls. This has greatly assisted BNL to build high quality magnets.

For all manufacturing at BNL, Northrop Grumman and Everson Electric there is systematic collection of test data during the manufacturing processes. These data are sent to BNL with each magnet, usually on computer disks, and are used as a basis for magnet acceptance. There are frequent discussions with our industrial partners regarding data trends and statistics. This has become a powerful tool in support of our supplier partnerships.

\section{ACCEPTANCE TEST RESULTS}

On receipt at $\mathrm{BNL}$ all magnets undergo a thorough test sequence to assure that they are acceptable for use in RHIC. These tests include mechanical, survey and electrical checks, and magnetic measurements at room temperature. The initial production of about 30 of each magnet or assembly is $100 \%$ cold-tested including quench and magnetic measurements. Thereafter, approximately $10 \%$ are randomly chosen for cold tests. However, $100 \%$ of the corrector magnets are cold-tested because of their fragile conductor.

\section{A. Quench Testing}

The $9.7 \mathrm{~m}$ long standard aperture arc dipoles are cold tested in their cryostats on horizontal test stands at the RHIC operating temperature of nominally $4.6 \mathrm{~K}$ obtained with supercritical helium gas at a mass flow rate of $100 \mathrm{~g} / \mathrm{s}$ and $5 \mathrm{~atm}$ pressure. Of 41 dipoles tested so far, all but two met a $30 \%$ margin goal of an acceptable stable plateau above $6500 \mathrm{~A}$ and those two were judged acceptable after further tests. Minimum quench currents are shown in Fig. 6.

The standard aperture quadrupoles are tested as cold masses in vertical dewars filled with liquid helium at a nominal $4.35 \mathrm{~K}$ and $1.12 \mathrm{~atm}$. Of 58 quadrupoles tested so far all have met the $30 \%$ margin goal. See Fig. 7 for minimum quench currents.

During cold tests, the standard aperture sextupole and trim quadrupole magnets typically train quickly to a plateau above the conductor limit of $200 \mathrm{~A}$, providing a $100 \%$ operating margin. Corrector magnets are all vertically tested. Dipole correctors are limited to $70 \mathrm{~A}$ during cold testing due to conductor heating at quench and normally easily reach that limit. The other correctors are tested with the dipole corrector at $70 \mathrm{~A}$ and easily reach $100 \mathrm{~A}$, a $100 \%$ operating margin.

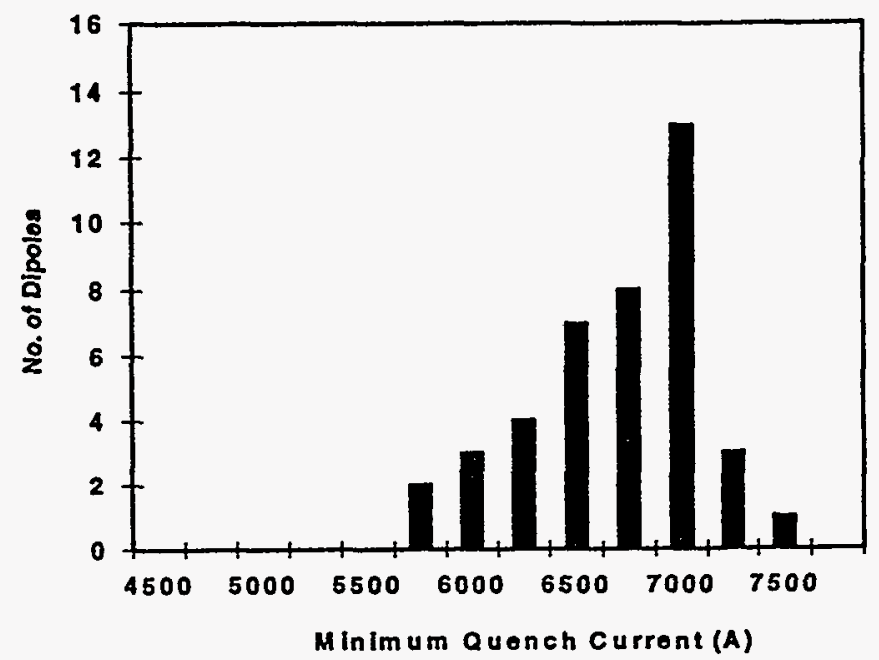

Fig. 6. Minimum quench currents for 41 standard aperture dipole magnets tested horizontally. RHIC operating current is $5000 \mathrm{~A}$. 


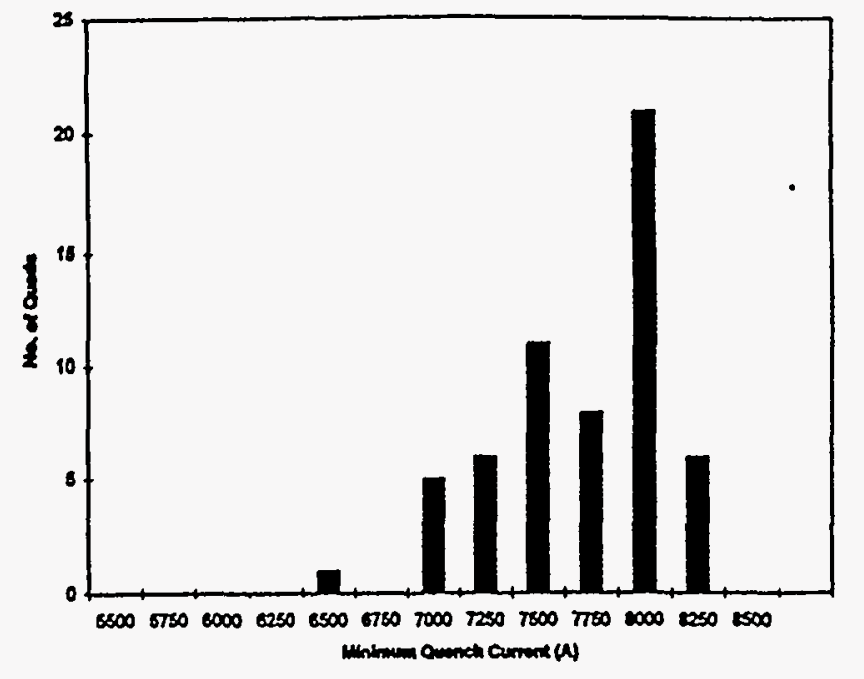

Fig. 7. Minimum quench currents for 58 standard aperture quadrupoles. RHIC operating current is $5000 \mathrm{~A}$.

\section{B. Magnetic Measurements}

All warm magnetic tests use rotating coil systems to determine the transfer functions and field quality. The integral transfer functions of the long arc dipoles are measured using a $10.4 \mathrm{~m}$ long non-rotating integral coil. Good warm-cold magnetic correlations for all the magnet types have been established [1].

The distribution of the integral transfer functions in the arc dipoles is shown in Fig. 8. The standard deviation of the distribution is $0.035 \%$ of the mean. The acceptable limit for the machine is $0.05 \%$. Fig. 9 shows the comelation between the normal sextupole terms measured warm and at $5 \mathrm{kA}$. The harmonics are measured in "units" of $10^{4}$ of the fundamental field and are expressed at a reference radius of $2.5 \mathrm{~cm}$. If the 5 $\mathrm{kA}$ values were identical to the warm values, the points would lie on the solid line shown in Fig. 9. The mean warm-cold difference is 3.3 units with a standard deviation of 0.2 units. Thus, the uncertainty in predicting the cold values from the warm values is about 0.2 units. The warm-cold offset is mostly due to superconductor magnetization and iron saturation effects in the cold measurements. :

Fig.10 shows the distribution of integral transfer functions in the arc quadrupoles measured warm. The distribution has a standard deviation of $0.05 \%$, which is acceptable for the machine. The fractional warm-cold difference in the transfer function has a standard deviation of about $0.03 \%$. This uncertainty in predicting the cold transfer functions from the warm values is about half of the width of the distribution.

The distributions of integral transfer functions in the sextupoles, and some of the corrector elements are shown in Figs. 11-13. All of these correction elements have acceptable field quality, with the most dominant harmonic terms being between $0.3 \%$ to $1 \%$ of the fundamental field.

Further details on the field quality of various magnets in RHIC can be found in several papers presented at a recent conference $[1,2,12]$.

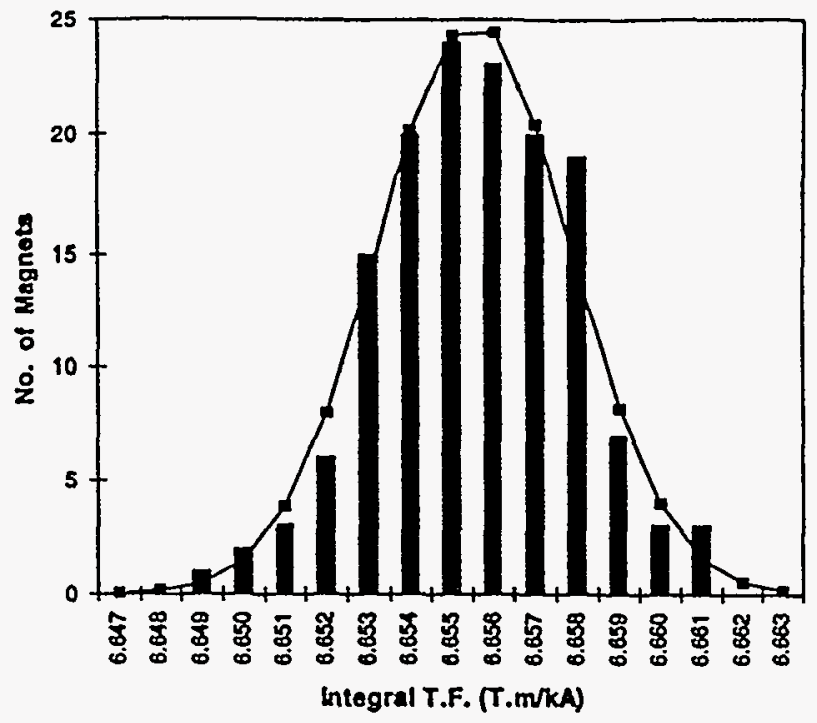

Fig. 8. Integral transfer function for 141 are dipoles measured wam. The boxes and line are expectations of a Gaussian distribution.

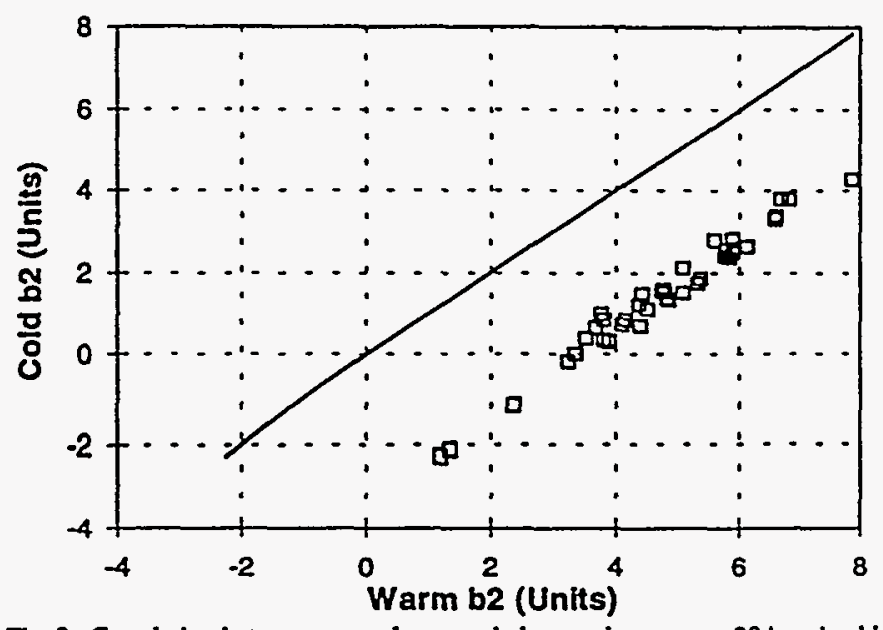

Fig. 9. Correlation between normal sexupole hamonic, warm at $30 \mathrm{~A}$ and cold at $5000 \mathrm{~A}$, for are dipole magnets.

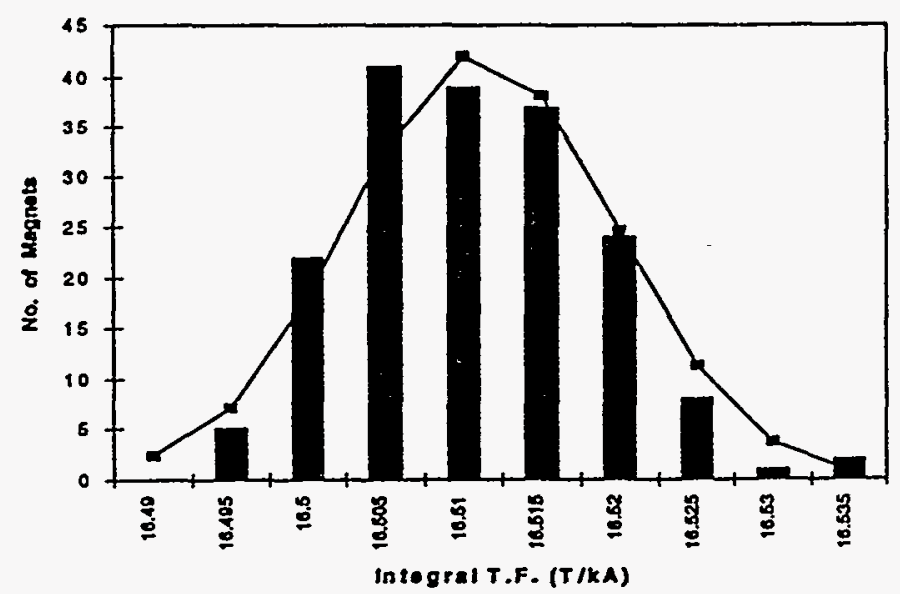

Fig. 10. Integral transfer function and predicted Gaussian distribution for 181 standard aperture quadrupole magnets measured warm. 


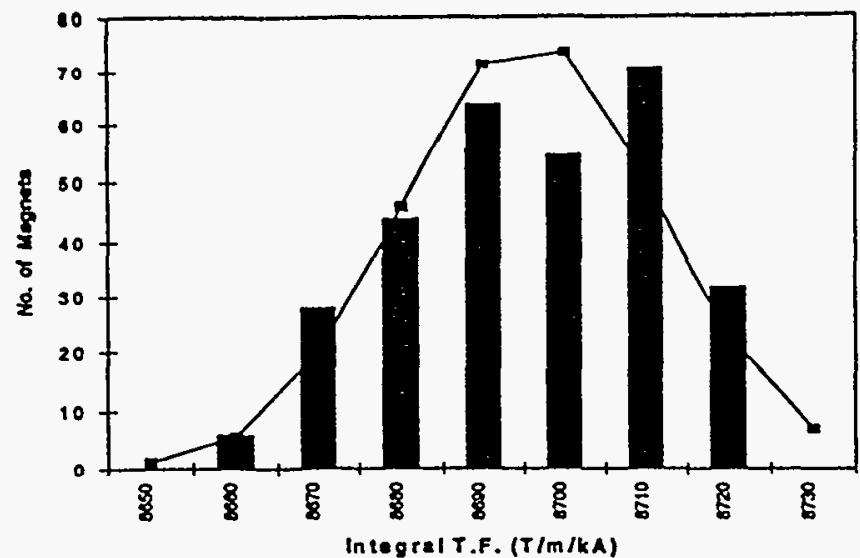

Fig. 11. Integral transfer and predicted Gaussian distribution for 300 standard aperture sextupole magnets measured warm.

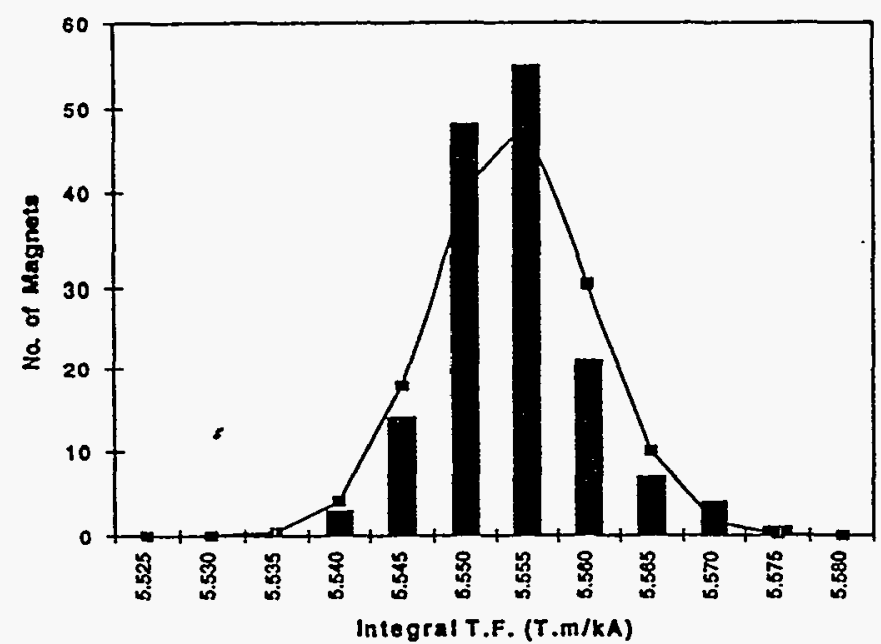

Fig. 12. Integral transfer function and predicted Gaussian distribution for 153 recent dipole correctors measured warm.

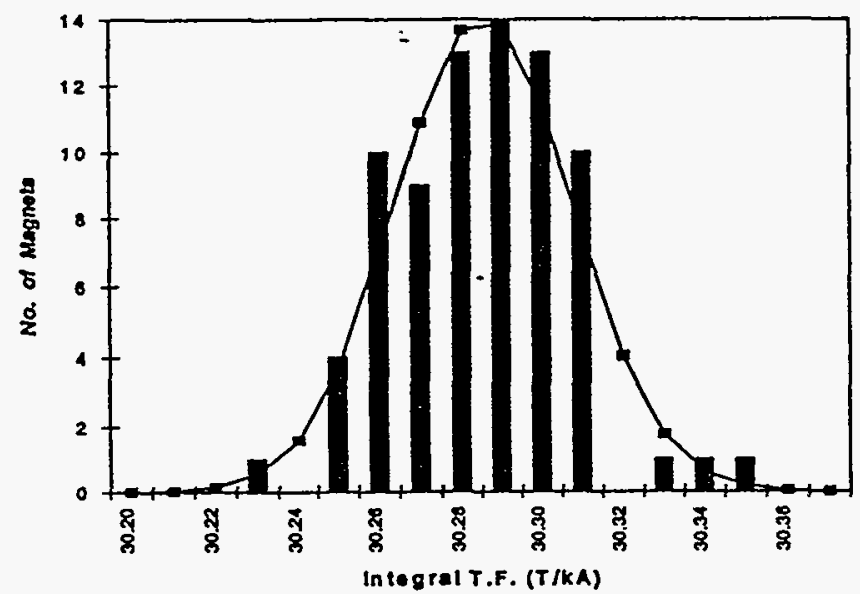

Fig. 13. Integral transfer function and predicted Gaussian distribution for 77 skew quadrupole correctors measured warm.

\section{v. CONCLUSIONS}

The production of magnets for RHIC is proceeding extremely well with the quality and performance of the many elements exceeding expectations. All magnet elements produced so far are acceptable for use in the accelerator. This indicates that the designs and approaches to manufacturing by BNL and industrial partners have been correct.

\section{ACKNOWLEDGMENTS}

It is a pleasure to acknowledge the ongoing contributions of the support staff at BNL that have contributed to the success of this magnet production. We also appreciate the strong, enthusiastic support provided by two contributing magnet manufacturers: Northrop Grumman and Everson Electric.

\section{REFERENCES}

P. Wanderer et al., "Construction and Testing of Arc Dipoles and Quadrupoles for the Relativistic Heavy Ion Collider (RHIC) at BNL", Proc. of the 1995 Intemational Particle Accelerator Conference, Dallas, Texas, May 1-5, 1995.

[2] R. Gupta et al., "Field Quality Control Through the Production Phase of the RHIC Arc Dipoles," ibid.

[3] M. Anerella et al., "Industrial Production of RHIC Magnets", to be presented at the Fourteenth International Conf. on Mag. Tech.June 1116. 1995. Tampere, Finland.

[4] A.F. Greene et al.., "Manufacture and Testing of the Superconducting Wire and Cable for the RHIC Dipoles and Quadrupoles", IEEE Trans. on Magnetics, (to be published as procedings for the Applied Superconductivity Conference, Boston 1994).

[5] M. Axerella et al., "Improved Cable Insulation for Superconducting Magnets," Proc. 1993 Particle Accelerator Conference (Washington, D.C.), pp.2790-2792.

[6] A. Jain \& al., "Skew Quadrupole in RHIC Dipole Magnets at High Fields", to be presented at the Fourteenth International Conf. on Mag. Tech., June 11-16, 1995, Tampere, Finland.

[7] S. Mulhall a al., "Combined Element Magnet Production for the Relativistic Heavy Ion Collider (RHIC) at BNL," Proc. of the 1995 International Particle Accelerator Conference, Dallas, Texas, May 1-5, 1995.

[8] A. Morgillo et al., "Superconducting $8 \mathrm{~cm}$ Corrector Magnets for the Relativistic Heavy Ion Collider (RHIC)", ibid.

[9] P. Thompson et al., "Superconducting Sextupoles and Tuning Quadrupoles for RHIC", ibid.

[10] R. Gupta et al., "Large Aperture Quadrupoles for RHIC Interaction Regions," Proc. of the 1993 Particle Accelerator Conference, Washington, D.C., May 17-20, 1993.

[11] R. Gupta et al., "Tuning Shims for High Field Quality in Superconducting Magnets", to be presented at the Fourteenth International Conf. on Mag. Tech., June 11-16, 1995, Tampere, Finland.

[12] J. Wei et al., "Field Quality Evaluation of the Superconducting Magnets of the Relativistic Heavy Ion Collider," Proc. of the 1995 International Particle Acoelerator Conference, Dallas, Texas, May 1.5, 1995. 